\title{
Effectiveness of telemedicine for pregnant women with gestational diabetes mellitus: an updated meta-analysis of 32 randomized controlled trials with trial sequential analysis
}

Weihua Xie ${ }^{1}$, Pinyuan Dai ${ }^{1}$, Yu Qin², Ming Wu${ }^{2}$, Bingquan Yang ${ }^{3}$ and Xiaojin Yu ${ }^{1 *}$

\begin{abstract}
Background: Gestational diabetes mellitus (GDM) is now a global health problem. Poor blood glucose control during pregnancy may lead to maternal and neonatal/foetal complications. Recently, the development of information and communication technology has resulted in new technical support for the clinical care of GDM. Telemedicine is defined as health services and medical activities provided by healthcare professionals through remote communication technologies. This study aimed to update the systematic review of the effectiveness of telemedicine interventions on glycaemic control and pregnancy outcomes in pregnant women with GDM.

Methods: We searched the Web of Science, PubMed, Scopus, Cochrane Central Register of Controlled Trials, Chinese National Knowledge Infrastructure, Wan-fang Database, China Biology Medicine and VIP Database for randomized controlled trials (RCTs) related to the effectiveness of telemedicine interventions for GDM from database inception to July 31st, 2019. Languages were limited to English and Chinese. Literature screening, data extraction and assessment of the risk of bias were completed independently by two reviewers. Meta-analysis and trial sequential analysis were conducted in Stata 14.0 and TSA v0.9.5.10 beta, respectively.
\end{abstract}

(Continued on next page)

\footnotetext{
* Correspondence: xiaojinyu@seu.edu.cn

'Department of Epidemiology and Health Statistics, School of Public Health,

Southeast University, Nanjing, China

Full list of author information is available at the end of the article
}

(c) The Author(s). 2020 Open Access This article is licensed under a Creative Commons Attribution 4.0 International License, which permits use, sharing, adaptation, distribution and reproduction in any medium or format, as long as you give appropriate credit to the original author(s) and the source, provide a link to the Creative Commons licence, and indicate if changes were made. The images or other third party material in this article are included in the article's Creative Commons licence, unless indicated otherwise in a credit line to the material. If material is not included in the article's Creative Commons licence and your intended use is not permitted by statutory regulation or exceeds the permitted use, you will need to obtain permission directly from the copyright holder. To view a copy of this licence, visit http://creativecommons.org/licenses/by/4.0/ The Creative Commons Public Domain Dedication waiver (http://creativecommons.org/publicdomain/zero/1.0/) applies to the data made available in this article, unless otherwise stated in a credit line to the data. 


\begin{abstract}
(Continued from previous page)
Results: A total of 32 RCTs were identified, with a total of 5108 patients. The meta-analysis showed that telemedicine group had significant improvements in controlling glycated haemoglobin (HbA1c) [mean difference $(\mathrm{MD})=-0.70, P<0.01]$, fasting blood glucose $(\mathrm{FBG})(\mathrm{MD}=-0.52, P<0.01)$ and 2 -h postprandial blood glucose $(2 \mathrm{hBG})(\mathrm{MD}=-1.03, P=0.01)$ compared to the corresponding parameters in the standard care group. In the telemedicine group, lower incidences of caesarean section [relative risk $(\mathrm{RR})=0.82, P=0.02$ ], neonatal hypoglycaemia $(R R=0.67, P<0.01)$, premature rupture of membranes $(R R=0.61, P<0.01)$, macrosomia $(R R=0.49$, $P<0.01)$, pregnancy-induced hypertension or preeclampsia $(R R=0.48, P<0.01)$, preterm birth $(R R=0.27, P<0.01)$, neonatal asphyxia $(R R=0.17, P<0.01)$, and polyhydramnios $(R R=0.16, P<0.01)$ were found. The trial sequential analyses conclusively demonstrated that the meta-analytic results of the change in $\mathrm{HbA} 1 \mathrm{c}$, the change in $2 \mathrm{hBG}$, the change in FBG, the incidence rates of caesarean section, pregnancy-induced hypertension or preeclampsia, premature rupture of membranes, premature birth, neonatal asphyxia, and polyhydramnios were stable.
\end{abstract}

Conclusions: Compared to standard care, telemedicine interventions can decrease the glycaemic levels of patients with GDM more effectively and reduce the risk of maternal and neonatal/foetal complications.

Keywords: Gestational diabetes mellitus, Telemedicine, Systematic review, Meta-analysis, Trial sequential analysis

\section{Background}

Gestational diabetes mellitus (GDM) is a common complication during pregnancy. According to the report of the International Diabetes Federation, the global prevalence of GDM in 2017 has reached 14.0\%, affecting nearly 21.3 million live births [1]. Johns et al. [2] reported that poor glycaemic control during pregnancy would increase the risk of maternal and neonatal/foetal complications, such as neonatal hypoglycaemia, macrosomia, preeclampsia, preterm birth, and polyhydramnios. Therefore, the blood glucose dynamics of pregnant women with GDM should be promptly reported to healthcare professionals for scientific guidance. Currently, the standard care practice for patients with GDM is that the pregnant women monitor the glycaemic levels and record by hand in paper diaries several times per day at home and then healthcare professionals review the glycaemic data and provide health education during the regular antenatal examination or face-to-face consultation [3-5]. The traditional mode of standard care has some shortcomings, such as lagging information and insufficient communication between doctors and patients. Recently, the rapid development of information and communication technology provides new technical support and management modes for improving the clinical care of patients [6-13]. Telemedicine (TM) refers to health services and medical activities, such as the remote evaluation, diagnosis and treatment of patients by healthcare professionals performed using remote communication technologies, such as mobile phones, Bluetooth, telephones, email, and websites. More specifically, healthcare professionals monitor patients' health-related indicators and provide timely medical feedback through website-based systems or mobile terminal devices, and remotely provide health knowledge and guidance to improve the physical and psychological status of patients [14, 15]. Ideally, TM facilitates the clinical management of diabetes by uploading glucose data, symptoms and signs in real-time and providing medical consultation and health education, which offers great convenience for patients in remote areas.

Most of the systematic reviews and meta-analyses on the use of telemedicine technologies for diabetes mellitus have demonstrated that TM tools could result in reduced HbA1c in individuals with type I, type II diabetes and GDM $[8,9,13,14,16]$. However, the effects of TM on other indices of glucose and pregnancy outcomes of the use of TM in patients with GDM remain uncertain [14, 17]. Rasekaba et al. [17] performed a meta-analysis of 3 RCTs comparing TM to standard care that included 228 pregnant women in 2015; the meta-analysis revealed no beneficial impacts of TM on glycated haemoglobin (HbA1c), 2-h postprandial blood glucose (2hBG) or the incidence of caesarean section. Moreover, the meta-analysis conducted by Ming et al. [14] revealed significant improvement in HbAlc and no differences in other maternal and neonatal outcomes between the TM group and the standard care group. In the last few years, some more studies that demonstrate the effects of TM in patients with GDM have been conducted. Guo et al. [6] reported that TM intervention could reduce the level of HbA1c more effectively but that it had no significant effect on fasting blood glucose (FBG) and 2hBG. Miremberg et al. [4] showed that mean blood glucose was reduced through the use of a TM intervention and no significant reduction in the incidence of pregnancy complications was reported. Nevertheless, some recent studies have also indicated the advantages of TM in the context of blood glucose $[3,18,19]$ and the incidence of caesarean section [7], preterm birth [20, 21], premature rupture of membranes [22], macrosomia [23] and neonatal hypoglycaemia $[19,24]$.

Given the inconsistencies among the results from recent studies, an updated meta-analysis with trial sequential analysis (TSA) was conducted to compare TM interventions 
with standard care in pregnant women with GDM. The aims of this study were evaluating the effectiveness of TM with the standard care in pregnant women with GDM, comparing the effects of different ways of TM, and selecting a better management mode for GDM. Subgroup analyses of studies according to the types of TM tools and the patterns of TM interventions were also carried out in this study to explore the potential source of the heterogeneity between studies and provide the estimates of effects for different ways of TM interventions.

\section{Methods}

\section{Search strategy and selection criteria}

We followed the Preferred Reporting Items for Systematic Reviews and Meta-Analysis (PRISMA) guidelines to perform the systematic review and meta-analysis [25] (completed PRISMA checklist is provided in Additional file 1). The Web of Science, PubMed, Scopus, Cochrane Central Register of Controlled Trials (CENTRAL), Chinese National Knowledge Infrastructure (CNKI), Wan-fang Database, China Biology Medicine (CBM) and VIP Database were used to search for relevant randomized controlled trials (RCTs) comparing TM to standard care from database inception to July 31st, 2019. We limited the language to English and Chinese. The search terms consisted of telemedicinerelated terms (mobile OR digital OR mhealth OR mhealth OR ehealth OR e-health OR app OR apps OR application* OR telemedicine OR tele-medicine OR smartphone OR smart phone OR cell phone OR telehealth OR tele-health OR tele-care OR telecare OR electronic* OR web-based OR technolog* OR short messag* OR SMS OR text message* OR texting OR remote OR internet OR WeChat OR QQ) and GDM-related terms (pregnan* diabet* OR gestation* diabet* OR pregnan* hypergly" OR gestation* hypergly" OR GDM). We also searched the reference lists of the identified studies. The Web of Science search strategy is listed in Additional file 2.

\section{Inclusion criteria}

Studies meeting the following criteria were included: (a) complete RCTs that enrolled pregnant women with GDM, (b) trials in which the patients in the trial group received the TM interventions and those in the control group received standard care, and (c) studies published in English or Chinese.

\section{Exclusion criteria}

Studies were excluded if (a) they were duplicate publications, literature reviews or meta-analyses, (b) they enrolled women with other types of diabetes, such as type I diabetes and type II diabetes, (c) they were non- randomized controlled trials, or (d) they had insufficient data for extraction.

\section{Outcomes}

The primary outcomes were the indicators of maternal glycaemic control during pregnancy, such as (1) glycated haemoglobin (HbA1c, \%), a form of haemoglobin that is bound to glucose, which reflects the average level of blood glucose over the past 2 to 3 months; (2) fasting blood glucose (FBG, $\mathrm{mmol} / \mathrm{L}$ ), the blood glucose level after fasting or not eating anything for at least $8 \mathrm{~h}$; and (3) 2-h postprandial blood glucose ( $2 \mathrm{hBG}, \mathrm{mmol} / \mathrm{L}$ ), the blood glucose level measured exactly $2 \mathrm{~h}$ after eating a meal. In this study, we calculated the difference in HbA1c, FBG, and 2hBG before and after the intervention as the change in HbA1c, FBG, and 2hBG.

The secondary outcomes were maternal and neonatal/ foetal complications, including the incidence of caesarean section, pregnancy-induced hypertension (PIH) or preeclampsia, premature rupture of membranes, macrosomia, admission to the neonatal intensive care unit (NICU), neonatal jaundice or hyperbilirubinemia, neonatal acute respiratory distress syndrome (NARDS), neonatal hypoglycaemia, preterm birth, neonatal asphyxia, and polyhydramnios.

\section{Study selection, data extraction, and quality assessment}

Two reviewers (WX and YQ) independently screened the literature, extracted the data and assessed the risk of bias of the included research. If there was any inconsistency, a decision was made by discussion. When screening the literature, we first excluded the obviously ineligible literature by reading the title and abstract, and then further read the full text to identify the studies to be included. The data extracted mainly comprised (1) the basic characteristics of the literature: the first author, the year of publication, the country or region, the sample size, etc., (2) the outcome indicators and related data, and (3) and the risk of bias of the study, which was evaluated by using the Cochrane Collaboration Risk of Bias Tool [26, 27], and included bias related to random sequence generation, allocation concealment, blinding of participants and personnel, blinding of outcome assessment, incomplete outcome data, selective reporting, and other bias.

\section{Data synthesis and analysis}

Meta-analysis was performed by Stata software (version 14, StataCorp, College Station, USA). The mean difference (MD) with the $95 \%$ confidence interval (CI) is presented for continuous data, where MD reflects the absolute difference between the average value in two groups in a clinical trial and estimates the average amount by which the trial intervention changed the 
outcome on average compared to the outcome of the control. The relative risk (RR) with the $95 \% \mathrm{CI}$ was calculated for binary categorical data, where RR is the ratio of the probability of a certain outcome occurring in two different groups and it describes the multiplication of the risk that occurs with the use of the trial intervention. Here, the smaller value of RR means a larger effect size for the TM interventions in reducing the risk of complication outcomes. The cut-off values of RR for small, medium and large effects are $0.82,0.54$ and 0.33 respectively [28].

The heterogeneity among the results was analysed by the Q-test (significance level $\alpha=0.10$ ) and quantitatively judged by the $\mathrm{I}^{2}$ statistic, where $\mathrm{I}^{2}>40 \%$ was considered to be evidence of substantial heterogeneity. If the heterogeneity among the results was statistically significant, the source of heterogeneity was further analysed and the random effect model was used for meta-analysis. If there was no significant heterogeneity among the results, the fixed-effect model was used. The sources of heterogeneity were explored by meta-regression (significance level $\alpha=0.10$ ). Subgroup analysis was conducted to explore the differences between different types of TM tools and patterns of TM interventions. Sensitivity analysis was conducted to assess the robustness of the pooled results after a study with high risk was removed. The significance level of the meta-analysis was set to 0.05. Moreover, funnel plots were used to evaluate publication bias. If the funnel plot is asymmetric, it suggests that there may be publication bias. Moreover, we used the standard deviation of the change to quantify the amount of variation in the changes in glycaemic levels (HbA1c, FBG, and 2hBG). The standard deviations of the change were calculated by the following formula:

$$
\mathrm{S}_{\mathrm{d}}=\sqrt{\mathrm{S}_{1}^{2}+\mathrm{S}_{2}^{2}-2 \times \mathrm{r} \times \mathrm{S}_{1} \times \mathrm{S}_{2}}
$$

where $S_{1}$ and $S_{2}$ denote the standard deviation of preand post-intervention, respectively. The correlation coefficient $(r)$ between measurements of pre- and postintervention was set to 0.5 in this study.

The trial sequential analysis (TSA) was carried out by using TSA software (version v0.9.5.10 beta, Copenhagen Trial Unit, Copenhagen, Denmark). In this study, the relative risk reduction (RRR), level of type I error and level of type II error were set to $20 \%, 0.05$ and 0.20 , respectively, to calculate the required information size (RIS). The monitoring boundary and futility boundary are presented to assess the evidence provided by each study sequentially. When the total sample size of the studies reaches the RIS or the cumulative $\mathrm{Z}$-value surpasses the monitoring boundary or futility boundary, it concludes that there is sufficient evidence regarding the effects of TM interventions from the meta-analysis.

\section{Results \\ Study selection process and basic characteristics of the included studies}

We initially identified 4047 publications from eight electronic databases. After screening the titles and abstracts and reviewing full texts, 32 RCTs were included: 13 English and 19 Chinese papers. The selection process is shown in Fig. 1.

A total of 5108 patients with GDM were included in this study, including the trial group $(n=2581)$ and the control group $(n=2527)$. Most studies were conducted in China (21 studies, 65.6\%). The sample size ranged from 44 to 820. TM interventions mainly consisted of web-based systems ( 7 trials), health devices ( 3 trials), health apps (7 trials), and WeChat (15 trials) (detailed descriptions are shown in Additional file 3). The basic characteristics and outcomes of each included study are listed in Table 1.

\section{Assessment of the risk of bias}

Methods of random sequence generation and allocation concealment were not clearly described in most of the included studies. Only 12 out of 32 studies described the methods of random sequence generation and six trials described allocation concealment, which may cause a high risk of bias in this study. The overall summary and individual risk of bias are given at length in Fig. 2.

\section{Glycaemic control}

The meta-analysis of 12 trials [3, 6, 18, 19, 21, 29, 30, 41$43,45,48]$ showed that the change in HbA1c in the TM group was higher than that in the control group $[\mathrm{MD}=$ $0.70,95 \% \mathrm{CI}=(-1.05,-0.34), P<0.01]$ with high heterogeneity $\left(\mathrm{I}^{2}=97 \%, P<0.01\right)$ (Fig. $\left.3 \mathrm{a}\right)$. The sensitivity analysis demonstrated that the pooled effect and $\mathrm{I}^{2}$ statistic changed minimally after item-by-item exclusion. Metaregression analysis showed that the gestational age at enrolment $(\beta=-0.07, P=0.05)$ and the location of the study ( $\beta=0.79, P=0.03$ ) might be the reasons for the high heterogeneity of the change in HbA1c.

The pooled effect of 20 trials [[3, 6, 7, 18, 19, 21, 22, $32,33,35,36,38,39,41-43,45-48]$ revealed a significant advantage in the TM group compared with the standard care group in regard to the change in FBG $[\mathrm{MD}=-0.52,95 \% \mathrm{CI}=(-0.81,-0.24), P<0.01]$ (Fig. 3b). Nevertheless, there was an obvious heterogeneity $\left(\mathrm{I}^{2}=\right.$ $94 \%, P<0.01)$ among studies. Sensitivity analysis showed the robustness of pooled effect and meta-regression did not reveal the source of heterogeneity.

The result of the meta-analysis of 15 studies $[6,18,19$, $21,22,35,36,38,39,41-43,45,47,48]$ indicated greater change in $2 \mathrm{hBG}$ in the TM group than that in the control 


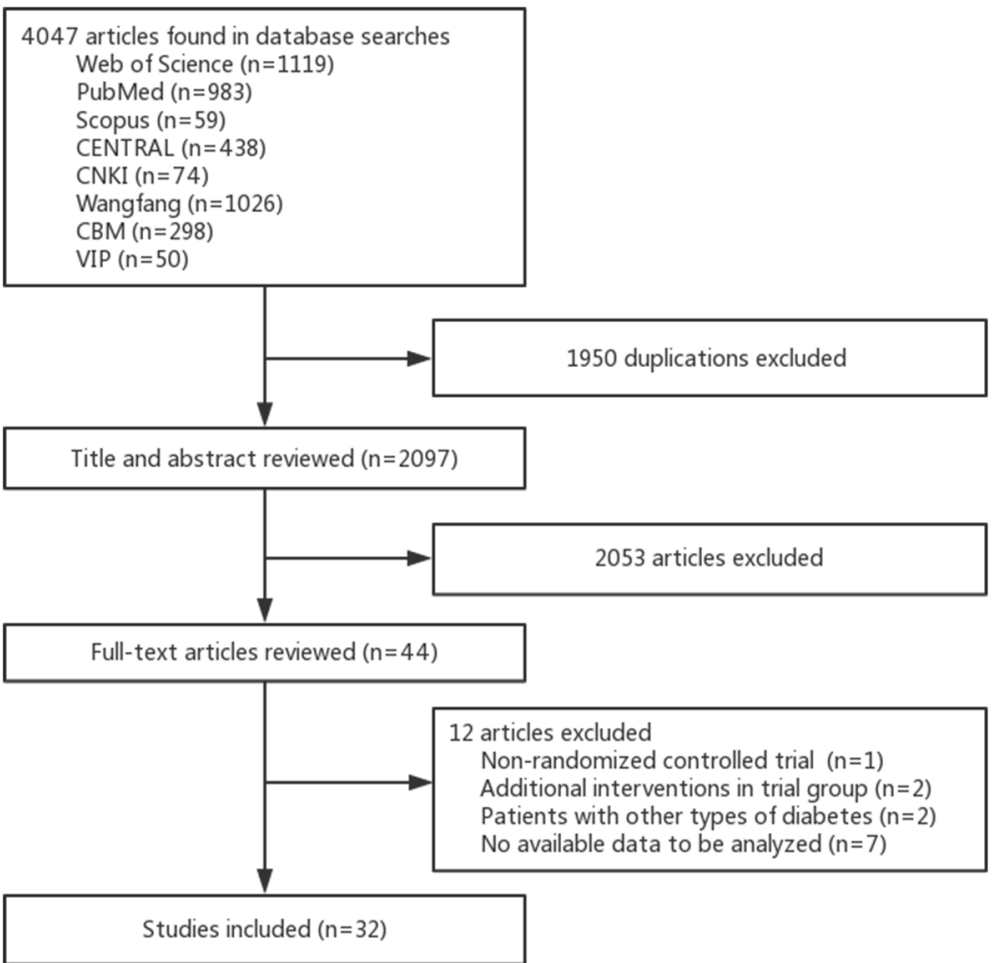

Fig. 1 Flow chart of the study selection process

group $[\mathrm{MD}=-1.03,95 \% \mathrm{CI}=(-1.83,-0.23), \quad P=0.01]$ (Fig. 3c). Significant inter-study heterogeneity $\left(\mathrm{I}^{2}=97 \%\right.$, $P<0.01)$ was observed, and the average age of pregnant women $(\beta=-0.19, P=0.08)$ and the gestational age at enrolment $(\beta=-0.22, P=0.07)$ were considered sources of heterogeneity according to the meta-regression.

\section{Maternal and neonatal/foetal complications}

Data from 19 trials $[4,6,7,19,23,30-32,34-36,40-44$, 46,48 ] involving 2374 pregnant women reported that TM interventions played a significant role in decreasing the incidence of the caesarean section when compared to the control condition $[R R=0.82,95 \% \mathrm{CI}=(0.69$, $0.97), P=0.02$ ] with mildly significant heterogeneity among studies $\left(\mathrm{I}^{2}=57 \%, P<0.01\right.$ ) (Table 2$)$. Sensitivity analysis revealed that the pooled effect on caesarean section was mainly influenced by three trials [32, 36, 46], but the specific sources of heterogeneity were not identified in the meta-regression. After excluding these three trials, the pooled $\mathrm{RR}$ and $\mathrm{I}^{2}$ statistic dropped to 0.72 $(P<0.01)$ and $15 \%$, respectively.

The pooled RR of 12 studies [4, 7, 20-22, 32-34, 36, $43,44,49]$ using a fixed effect model showed that the incidence of PIH or preeclampsia in the TM group was significantly lower than that in the control group $[R R=$ $\left.0.48,95 \% \mathrm{CI}=(0.40,0.58), P<0.01 ; \mathrm{I}^{2}=11 \%, P=0.34\right]$.
The results of meta-analysis of 7 trials [22, 32, 33, 36, $41,46,49]$ using a fixed-effect model showed that the incidence of premature rupture of membranes in the TM group was significantly lower than that in the control group $[R R=0.61,95 \% \mathrm{CI}=(0.50,0.76), P<0.01]$, with insignificant heterogeneity among studies $\left(\mathrm{I}^{2}=15 \%, P=\right.$ $0.31)$.

The pooled result of eighteen studies [6, 7, 19-24, 30, $31,35-37,41,43,44,47,49]$ confirmed that TM interventions could significantly reduce the risk of macrosomia compared to the standard care $[R R=0.49,95 \% \mathrm{CI}=(0.30$, $0.80), P<0.01]$, with substantial heterogeneity $\left(\mathrm{I}^{2}=77\right.$, $P<0.01)$. Two trials $[7,22]$ were identified as sources of heterogeneity by sensitivity analysis. In comparison to the rest of the included studies, the study conducted by Mackillop et al. [7] included patients with an older age (33.5 years old) and higher gestational age at enrolment (31 weeks) on average, and Su et al's trial [22] had the largest number of patients $(n=820)$. The re-pooled results showed no significant heterogeneity after removing these two trials at the same time $\left(\mathrm{I}^{2}=27 \%, P=0.15\right)$. Furthermore, meta-regression illustrated that the heterogeneity among studies might be caused by sample size $(\beta=-0.01$, $P=0.06)$, the location of study $(\beta=1.42, P<0.01)$, the average age of pregnant women $(\beta=0.26, P=0.02)$, gestational age at enrolment $(\beta=0.15, P=0.04)$ and the proportion of primipara $(\beta=-5.39, P=0.08)$. 
Table 1 Basic characteristics and outcomes of included studies

\begin{tabular}{|c|c|c|c|c|c|c|c|}
\hline Study & Country/region & $\begin{array}{l}\text { Sample size } \\
\text { (Trial/Control) }\end{array}$ & TM intervention ${ }^{a}$ & $\begin{array}{l}\text { Mean age } \\
\text { (year) }\end{array}$ & $\begin{array}{l}\text { College } \\
\text { education (\%) }\end{array}$ & $\begin{array}{l}\text { Gestational age at } \\
\text { enrolment (week) }\end{array}$ & Outcome $^{b}$ \\
\hline Carral 2015 [29] & Spain & $77(30 / 47)$ & $\begin{array}{l}\text { Web-based } \\
\text { system }\end{array}$ & 33.8 & 22.1 & 21.1 & (1) \\
\hline Dalfra 2009 [30] & Italy & $203(88 / 115)$ & Health device & 34.0 & - & 28.0 & (1)(4) \\
\hline Given 2015 [31] & $\begin{array}{l}\text { North Ireland and } \\
\text { Ireland }\end{array}$ & $50(24 / 26)$ & Health device & 31.7 & - & 28.0 & (4) (7)(2)(1012) \\
\hline Guo 2019 [6] & China & $124(64 / 60)$ & Health app & 30.9 & 55.6 & 24.9 & (1)(2)(3)(4)(7)(11) \\
\hline Homko 2007 [32] & USA & $57(32 / 25)$ & $\begin{array}{l}\text { Web-based } \\
\text { system }\end{array}$ & 29.5 & 43.9 & 27.6 & (2)(4)(5)(6)(9)(10)(11) \\
\hline Homko 2012 [33] & USA & $80(40 / 40)$ & $\begin{array}{l}\text { Web-based } \\
\text { system }\end{array}$ & 30.2 & 60.0 & 28.5 & (2)(4)(5)(6)(910(1)(12) \\
\hline Mackillop 2018 [7] & UK & $\begin{array}{l}203(101 / \\
102)\end{array}$ & Health app & 33.5 & 48.5 & 31.0 & (2)(4)(5)(7)9(11) (12) \\
\hline Miremberg 2018 [4] & Israel & $120(60 / 60)$ & Health app & 31.9 & 32.5 & - & (4)(5)(8)(1011(14) \\
\hline $\begin{array}{l}\text { Perez-Ferre } 2010 \\
\text { [34] }\end{array}$ & Spain & $97(49 / 48)$ & Health app & 33.8 & 15.5 & - & (4)(5)(11) (12) \\
\hline Rasekaba 2018 [35] & Australia & $95(61 / 34)$ & $\begin{array}{l}\text { Web-based } \\
\text { system }\end{array}$ & 32.0 & - & 28.0 & (2)(3)(4)(8) \\
\hline Yang 2018 [36] & China & $107(57 / 50)$ & WeChat & 31.9 & - & - & (2)(3)(4)(5)(6)(7)(9)(11)(12) \\
\hline $\begin{array}{l}\text { Carolan-Olah } 2019 \\
\text { [37] }\end{array}$ & Australia & $110(52 / 58)$ & $\begin{array}{l}\text { Web-based } \\
\text { system }\end{array}$ & 31.7 & 47.3 & $28-30$ & (7) \\
\hline Kim 2019 [3] & Korea & $44(22 / 22)$ & $\begin{array}{l}\text { Web-based } \\
\text { system }\end{array}$ & 35.8 & 97.7 & 27.4 & (1)(2) \\
\hline Gao 2017 [18] & China & $58(28 / 30)$ & Health app & 27.8 & 31.0 & - & (1)(2)(3) \\
\hline Hua 2018 [19] & China & $120(60 / 60)$ & WeChat & 27.6 & 25.8 & 24.0 & (1)(2)(3)(4)(7)(11) \\
\hline Zhang 2018 [38] & China & $80(40 / 40)$ & Health app & 29.5 & - & 26.9 & (2)(3) \\
\hline Zhao 2018 [39] & China & $60(30 / 30)$ & Health app & - & - & - & (2)(3) \\
\hline Zeng 2017 [40] & China & $86(43 / 43)$ & WeChat & - & 74.4 & - & (4)(11) \\
\hline Fang 2017 [41] & China & $60(30 / 30)$ & WeChat & 30.8 & - & 23.0 & (1)(2)(3)(4)(6)(9)(11)(2)(13) \\
\hline Ge 2017 [23] & China & $\begin{array}{l}586(308 / \\
278)\end{array}$ & WeChat & 30.5 & 45.1 & 26.0 & (4)(7) \\
\hline Huang 2016 [42] & China & $80(40 / 40)$ & WeChat & 39.0 & 28.8 & 36.7 & (1)(2)(3)(4) \\
\hline Jiang 2017 [43] & China & $150(78 / 72)$ & WeChat & 28.0 & - & 29.5 & (1)(2)(3)(4)(5)(7)(10(1)(4) \\
\hline Jiang 2019 [44] & China & $\begin{array}{l}200(100 / \\
100)\end{array}$ & WeChat & 28.7 & - & - & (4)(5)(7)(12)(13)(14) \\
\hline Jiang 2016 [20] & China & $120(60 / 60)$ & WeChat & 25.3 & - & 22.8 & (5)(1)(12)(14) \\
\hline Liu 2018 [45] & China & $98(49 / 49)$ & Health device & 27.8 & - & 30.3 & (1)(2) \\
\hline Lu 201 [21] & China & $\begin{array}{l}280(140 / \\
140)\end{array}$ & WeChat & 26.1 & 47.9 & - & (1)(2)(3)(5)(7)(12)(13)(14) \\
\hline Luo 2017 [46] & China & $107(57 / 50)$ & WeChat & 31.9 & - & - & (2)(4)(6) \\
\hline Shao 2018 [47] & China & $\begin{array}{l}410(205 / \\
205)\end{array}$ & WeChat & 30.5 & 52.9 & - & (2)(3) \\
\hline Su 2018 [22] & China & $\begin{array}{l}820(420 / \\
400)\end{array}$ & $\begin{array}{l}\text { Web-based } \\
\text { system }\end{array}$ & 28.2 & 27.0 & - & (2)(3)(5)(6) (7)(12)(13)(14) \\
\hline Weng 2018 [48] & China & $120(60 / 60)$ & WeChat & 39.5 & 53.3 & 36.6 & (1)(2)(3)(4) \\
\hline Xiao 2016 [24] & China & $\begin{array}{l}206(103 / \\
103)\end{array}$ & WeChat & 29.7 & - & 26.4 & (2)(11) \\
\hline Yang 2015 [49] & China & $100(50 / 50)$ & WeChat & 30.0 & 80.0 & - & (5)(6)(7)(12)(13)(14) \\
\hline
\end{tabular}

a TM intervention: Detailed descriptions are listed in Additional file 3. ${ }^{\mathrm{b}}$ Outcome: (1)change of HbA1c; (2)change in FBG; (3)change in 2hBG; (4) caesarean section; (5)pregnancy induced hypertension or preeclampsia; (-premature rupture of membranes; (7)macrosomia; (8admission to the NICU; (9neonatal jaundice or hyperbilirubinemia; (10NARDS; (11)neonatal hypoglycaemia; (12)preterm birth; (B)neonatal asphyxia; (4)polyhydramnios 


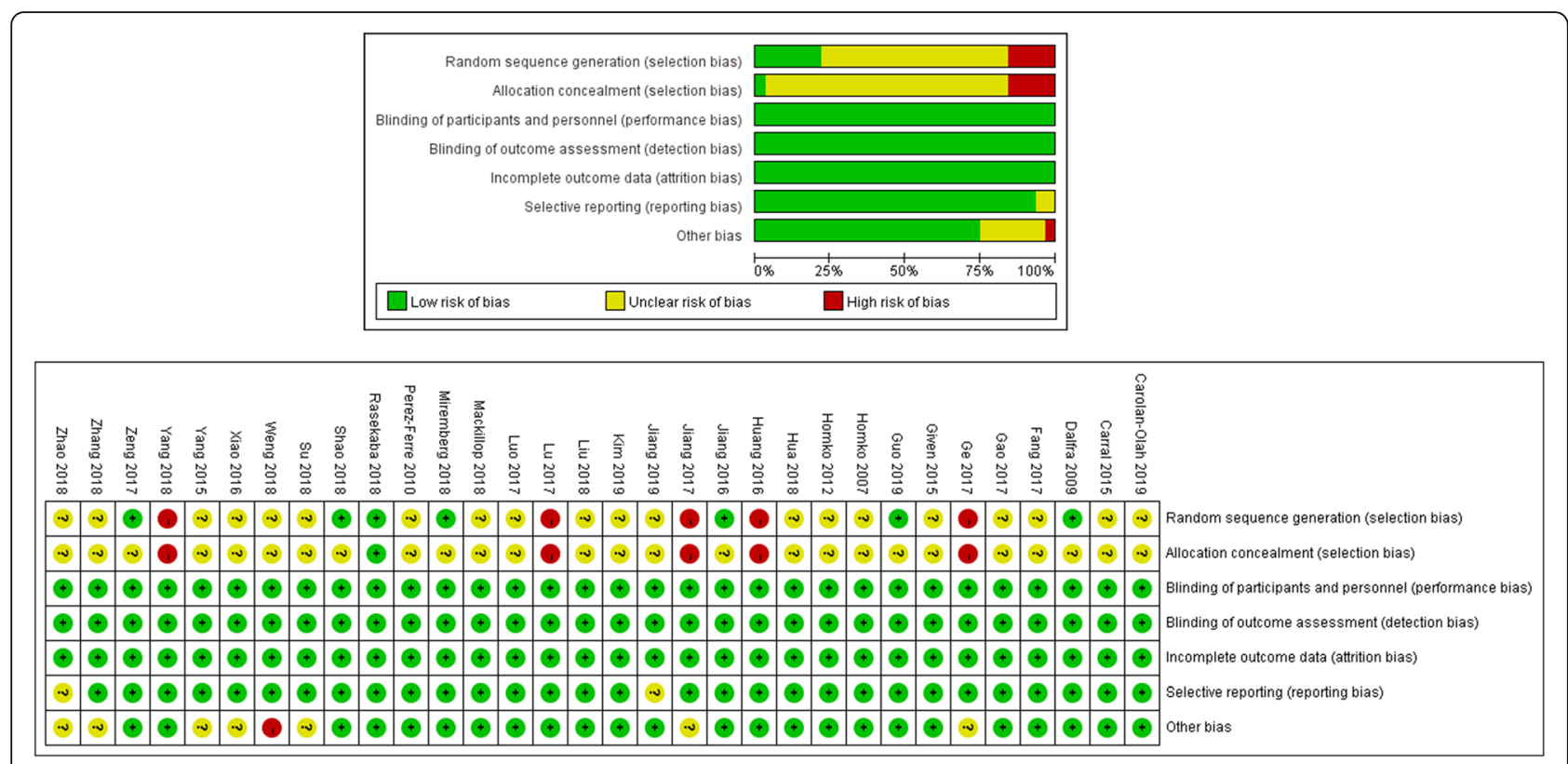

Fig. 2 Assessment of risk of bias

The results of a meta-analysis of 12 trials [4, 6, 7, 19, 24, 32-34, 36, 40, 41, 43] using a random effect model showed that the incidence of neonatal hypoglycaemia in the TM group was significantly lower than that in the control group $\left[R R=0.67,95 \% \mathrm{CI}=(0.51,0.87), P<0.01 ; \mathrm{I}^{2}=39 \%, P=\right.$ 0.08]. In the meta-analysis of 13 trials [7, 19-22, 31-34, 36, $41,44,49]$, there was a significantly lower risk of preterm birth in the TM group than in the standard care group $[R R=$ $\left.0.27,95 \% \mathrm{CI}=(0.20,0.35), P<0.01 ; \mathrm{I}^{2}=38 \%, P=0.08\right]$.

The meta-analysis of five studies [21, 22, 41, 44, 49] found sufficient evidence of a beneficial effect of TM interventions on the incidence of neonatal asphyxia $[R R=$ $0.17,95 \% \mathrm{CI}=(0.08,0.33), P<0.01]$, and no significant heterogeneity was present among these studies $\left(\mathrm{I}^{2}=0\right.$, $P=0.85$ ). The pooled effect of 7 trials $[4,20-22,43,44$, $49]$ indicated that there was significant reduction in the risk of polyhydramnios in the TM group $[R R=0.16,95 \%$ $\mathrm{CI}=(0.10,0.28), P<0.01]$, without the existence of heterogeneity $\left(\mathrm{I}^{2}=0, P=0.99\right)$.

The overall result of the meta-analysis demonstrated no significant reduction in the risk of the incidence of admission to the NICU $[4,7,31-33,35,36]$, neonatal jaundice or hyperbilirubinemia $[7,31-33,36,41]$, or NARDS [7, $31-33,36,41]$ between the two groups $[R R=0.89,95 \%$ $\mathrm{CI}=(0.60,1.32), P=0.57 ; \mathrm{RR}=1.00,95 \% \mathrm{CI}=(0.64,1.55)$, $\mathrm{P}=0.99 ; R R=0.66,95 \% \mathrm{CI}=(0.33,1.33), P=0.25$, respectively], without significant heterogeneity $\left(\mathrm{I}^{2}=20 \%, P=0.28\right.$; $\mathrm{I}^{2}=0, P=0.68 ; \mathrm{I}^{2}=0, P=0.41$, respectively), (Table 2).

\section{Subgroup analysis}

For the subgroup analysis, we identified three subgroups for each outcome indicator corresponding to three types of TM tools, including health app or device, web-based system, and WeChat (Table 3). Only the subgroups with more than 2 trials were analysed. Patients receiving WeChat interventions were considered to benefit more than those receiving interventions using health app or device and web-based system in regard to the change in HbA1c, the change in FBG, and the incidence of PIH or preeclampsia, macrosomia, and neonatal hypoglycaemia. The health app or device subgroup exhibited a greater reduction in the incidence of caesarean section than the web-based system and WeChat. Compared with standard care, health app or device could significantly reduce 2hBG, but no significant difference was found in the WeChat subgroup. Regarding the incidence of premature rupture of membranes and the incidence of preterm birth, the web-based system reduced the risk more effectively than health app or device and WeChat. Furthermore, low heterogeneity existed in the subgroup of health app or device on the change in FBG, the change in $2 \mathrm{hBG}$, the incidence of caesarean section and macrosomia, and little heterogeneity $\left(\mathrm{I}^{2}=4 \%\right)$ was found in the subgroup analysis of the effect of WeChat on the incidence of macrosomia.

In addition, we divided all the studies into four subgroups according to the patterns of TM interventions in the study; the subgroups consisted of group 1 (real-time monitoring and feedback), group 2 (health education and question answering), group 3 (real-time monitoring and feedback + health education and question answering) and group 4 (real-time monitoring and feedback + health education and question answering + peer support) (Table 4). Regarding the change in FBG, the change in $2 \mathrm{hBG}$, and 
A

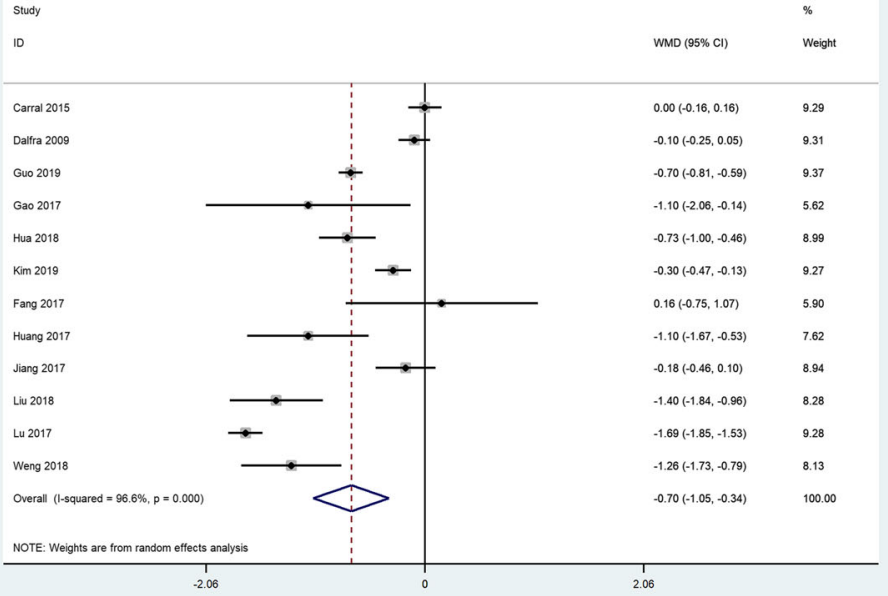

B

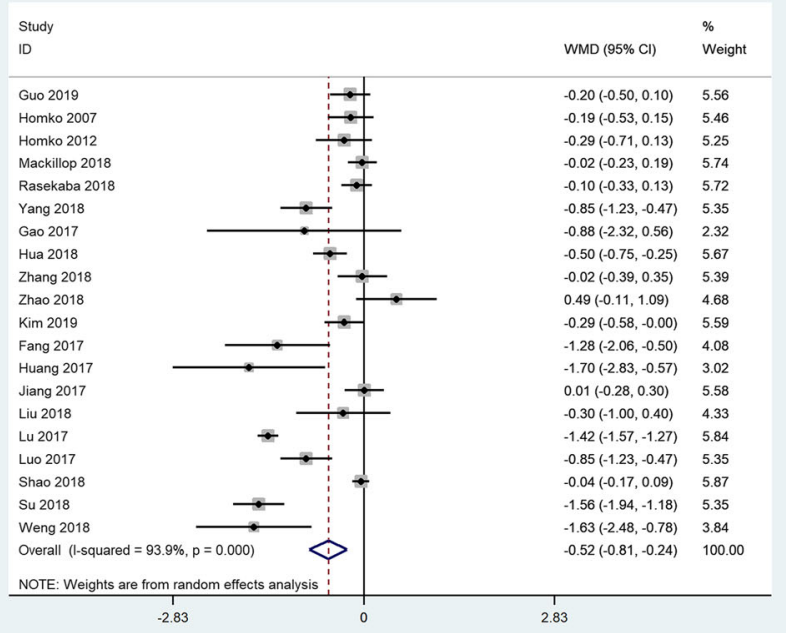

C

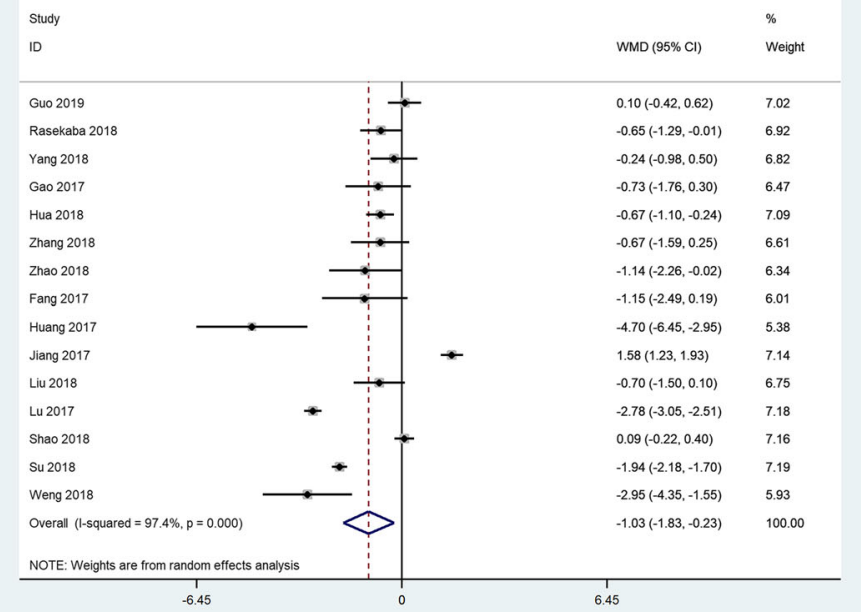

Fig. 3 The meta-analyses of the change in $\mathrm{HbA1c}(\mathbf{a}), \mathrm{FBG}(\mathbf{b})$ and $2 \mathrm{hBG}(\mathbf{c})$ 
Table 2 Meta-analyses of maternal/foetal outcomes of TM interventions compared to standard care in patients with GDM

\begin{tabular}{|c|c|c|c|c|c|c|}
\hline \multirow[t]{2}{*}{ Outcome } & \multirow[t]{2}{*}{ No. of trials } & \multicolumn{3}{|c|}{ Pooled effect } & \multicolumn{2}{|c|}{ Heterogeneity } \\
\hline & & Effect size & $95 \% \mathrm{Cl}$ & $P$ & $\mathrm{1}^{2}$ & $P$ \\
\hline Caesarean section & $19[4,6,7,19,23,30-32,34-36,40-44,46,48]$ & $\mathrm{RR}=0.82$ & $(0.69,0.97)$ & 0.02 & 57 & 0.01 \\
\hline $\mathrm{PIH}$ or preeclampsia & $12[4,7,20-22,32-34,36,43,44,49]$ & $\mathrm{RR}=0.48$ & $(0.40,0.58)$ & $<0.01$ & 11 & 0.34 \\
\hline Premature rupture of membranes & $7[22,32,33,36,41,46,49]$ & $\mathrm{RR}=0.61$ & $(0.50,0.76)$ & $<0.01$ & 15 & 0.31 \\
\hline Macrosomia & $18[6,7,19-24,30,31,35-37,41,43,44,47,49]$ & $\mathrm{RR}=0.49$ & $(0.30,0.80)$ & $<0.01$ & 77 & $<0.01$ \\
\hline Neonatal hypoglycaemia & $12[4,6,7,19,24,32-34,36,40,41,43]$ & $R R=0.67$ & $(0.51,0.87)$ & $<0.01$ & 39 & 0.08 \\
\hline Preterm birth & $13[7,19-22,31-34,36,41,44,49]$ & $\mathrm{RR}=0.27$ & $(0.20,0.35)$ & $<0.01$ & 38 & 0.08 \\
\hline Neonatal asphyxia & $5[21,22,41,44,49]$ & $\mathrm{RR}=0.17$ & $(0.08,0.33)$ & $<0.01$ & 0 & 0.85 \\
\hline Polyhydramnios & $7[4,20-22,43,44,49]$ & $\mathrm{RR}=0.16$ & $(0.10,0.28)$ & $<0.01$ & 0 & 0.99 \\
\hline Admission to the NICU & $7[4,7,31-33,35,36]$ & $\mathrm{RR}=0.89$ & $(0.60,1.32)$ & 0.57 & 20 & 0.28 \\
\hline Neonatal jaundice or hyperbilirubinemia & $6[7,31-33,36,41]$ & $\mathrm{RR}=1.00$ & $(0.64,1.55)$ & 0.99 & 0 & 0.68 \\
\hline NARDS & $6[7,31-33,36,41]$ & $\mathrm{RR}=0.66$ & $(0.33,1.33)$ & 0.25 & 0 & 0.41 \\
\hline
\end{tabular}

GDM Gestational diabetes mellitus, PIH pregnancy-induced hypertension, NICU neonatal intensive care unit, NARDS neonatal acute respiratory distress syndrome, $R R$ relative risk, $C l$ confidence interval, $T M$ telemedicine

the incidence of caesarean section, PIH or preeclampsia, macrosomia, and preterm birth, the more comprehensive patterns of TM interventions (group 3 and 4) were indeed more effective than the simple patterns of TM interventions (group 1 and 2).

\section{Publication bias}

Funnel plots show that there might be publication bias in studies involving the incidence of caesarean section (Fig. 4), but no significant publication bias was found in the studies of the other 13 outcomes.

\section{Trial sequential analysis}

Figure $5 \mathrm{a}-\mathrm{d}$ shows the TSA results of the change in $2 \mathrm{hBG}$, the change in FBG, the incidence of neonatal hypoglycaemia and the incidence of admission to the NICU, respectively. The cumulative $Z$-value of the change in $2 \mathrm{hBG}$ surpassed the monitoring boundary, and the incidence of PIH or preeclampsia, premature rupture of membranes, premature birth, neonatal asphyxia, and polyhydramnios exhibited similar results. Moreover, the cumulative sample size of the change in FBG met the RIS which was similar to the change in HbA1c and the incidence of caesarean section. In addition, the cumulative $\mathrm{Z}$ values of the incidence of macrosomia and neonatal hypoglycaemia did not reach the monitoring boundary or the RIS line, and the cumulative $\mathrm{Z}$ values of the incidence of admission to the NICU, neonatal jaundice or hyperbilirubinemia, and NARDS did not surpass the futility boundary or the RIS.

\section{Discussion}

The development of information and communications technology and the popularization of intelligent devices have resulted in a brand-new reform in medical treatment and clinical care. Increasing attention has been paid to the effectiveness of TM on GDM worldwide. This updated meta-analysis of 32 RCTs systematically evaluated the effectiveness of TM interventions compared with that of standard care on glycaemic control and pregnancy outcomes in patients with GDM. This study indicated that TM interventions can contribute to favourable impacts on HbA1c, FBG, and 2hBG. Regarding pregnancy outcomes, we found that TM interventions were inversely associated with the risk of caesarean section, PIH or preeclampsia, premature rupture of membranes, preterm birth, neonatal asphyxia, polyhydramnios, macrosomia, and neonatal hypoglycaemia. Moreover, the meta-analyses of studies involving the admission to the NICU, neonatal jaundice or hyperbilirubinemia and NARDS did not confirm significant differences between the two groups.

Two earlier meta-analyses on TM for the management of diabetes during pregnancy have previously been published. Ming et al. [14] carried out a meta-analysis of 7 RCTs with 579 pregnant women with any form of diabetes in pregnancy in 2016 and concluded that there was a significant difference in HbA1c between the TM group and the standard care group, and no effect was found in other maternal or neonatal outcomes. Rasekaba et al. [17] performed a meta-analysis of 3 RCTs involving 228 pregnant women with only GDM comparing TM to standard care in 2015 and found no beneficial impacts of TM on glycaemic control or pregnancy outcomes. By identifying and including additional recent trials with GDM only, the understanding of TM management of GDM was updated and more significant differences in maternal and neonatal/foetal complications were confirmed, which could provide scientific guidelines for future TM management. The greatest potential of TM lies in its ability to help patients who cannot be easily treated 
Table 3 Subgroup analyses of studies using different types of TM tools

\begin{tabular}{|c|c|c|c|c|c|c|c|}
\hline \multirow[t]{2}{*}{ Outcome } & \multirow[t]{2}{*}{ TM tools } & \multirow{2}{*}{$\begin{array}{l}\text { No. } \\
\text { of } \\
\text { trials }\end{array}$} & \multicolumn{3}{|c|}{ Pooled effect } & \multicolumn{2}{|c|}{ Heterogeneity } \\
\hline & & & Effect size & $95 \% \mathrm{Cl}$ & $P$ & $\overline{1^{2}}$ & $P$ \\
\hline \multirow[t]{2}{*}{ Change in $\mathrm{HbA} 1 \mathrm{c}$} & Health app or device & 4 & $\mathrm{MD}=-0.75$ & $(-1.25,-0.25)$ & $<0.01$ & 95 & 0.01 \\
\hline & WeChat & 6 & $M D=-0.84$ & $(-1.46,-0.22)$ & $<0.01$ & 95 & $<0.01$ \\
\hline \multirow[t]{3}{*}{ Change in FBG } & Health app or device & 6 & $M D=-0.05$ & $(-0.23,0.12)$ & 0.54 & 16 & 0.31 \\
\hline & Web-based system & 5 & $M D=-0.48$ & $(-0.95,-0.00)$ & 0.05 & 91 & $<0.01$ \\
\hline & WeChat & 9 & $M D=-0.85$ & $(-1.35,-0.35)$ & $<0.01$ & 96 & $<0.01$ \\
\hline \multirow[t]{2}{*}{ Change in $2 \mathrm{hBG}$} & Health app or device & 5 & $M D=-0.50$ & $(-0.97,-0.03)$ & 0.04 & 38 & 0.17 \\
\hline & WeChat & 8 & $M D=-1.26$ & $(-2.63,0.11)$ & 0.07 & 98 & $<0.01$ \\
\hline \multirow[t]{3}{*}{ Caesarean section } & Health app or device & 6 & $R R=0.76$ & $(0.60,0.97)$ & 0.03 & 33 & 0.19 \\
\hline & Web-based system & 3 & $\mathrm{RR}=1.19$ & $(0.69,2.06)$ & 0.54 & 67 & 0.05 \\
\hline & WeChat & 10 & $\mathrm{RR}=0.82$ & $(0.60,0.96)$ & 0.02 & 56 & 0.02 \\
\hline \multirow[t]{3}{*}{ PIH or preeclampsia } & Health app or device & 3 & $R R=0.76$ & $(0.28,2.09)$ & 0.60 & 35 & 0.22 \\
\hline & Web-based system & 3 & $\mathrm{RR}=0.50$ & $(0.40,0.62)$ & $<0.01$ & 70 & 0.04 \\
\hline & WeChat & 6 & $R R=0.39$ & $(0.26,0.61)$ & $<0.01$ & 0 & 0.93 \\
\hline \multirow[t]{2}{*}{ Premature rupture of membranes } & Web-based system & 3 & $\mathrm{RR}=0.56$ & $(0.44,0.71)$ & $<0.01$ & 21 & 0.28 \\
\hline & WeChat & 3 & $R R=0.80$ & $(0.53,1.19)$ & 0.27 & 0 & 0.51 \\
\hline \multirow[t]{3}{*}{ Macrosomia } & Health app or device & 4 & $\mathrm{RR}=1.16$ & $(0.65,2.06)$ & 0.62 & 27 & 0.25 \\
\hline & Web-based system & 3 & $\mathrm{RR}=0.61$ & $(0.07,5.58)$ & 0.66 & 81 & $<0.01$ \\
\hline & WeChat & 11 & $\mathrm{RR}=0.44$ & $(0.32,0.59)$ & $<0.01$ & 4 & 0.40 \\
\hline \multirow[t]{2}{*}{ Admission to the NICU } & Health app or device & 3 & $\mathrm{RR}=0.74$ & $(0.44,1.24)$ & 0.25 & 14 & 0.32 \\
\hline & Web-based system & 3 & $\mathrm{RR}=1.33$ & $(0.69,2.59)$ & 0.40 & 46 & 0.16 \\
\hline \multirow[t]{2}{*}{ Neonatal hypoglycaemia } & Health app or device & 4 & $\mathrm{RR}=1.25$ & $(0.81,1.92)$ & 0.31 & 0 & 0.78 \\
\hline & WeChat & 6 & $\mathrm{RR}=0.40$ & $(0.28,0.59)$ & $<0.01$ & 0 & 0.86 \\
\hline \multirow[t]{3}{*}{ Preterm birth } & Health app or device & 3 & $\mathrm{RR}=0.40$ & $(0.17,0.96)$ & 0.04 & 0 & 0.75 \\
\hline & Web-based system & 3 & $\mathrm{RR}=0.22$ & $(0.15,0.32)$ & $<0.01$ & 84 & $<0.01$ \\
\hline & WeChat & 7 & $\mathrm{RR}=0.32$ & $(0.21,0.48)$ & $<0.01$ & 0 & 0.66 \\
\hline Neonatal asphyxia & WeChat & 4 & $\mathrm{RR}=0.17$ & $(0.08,0.33)$ & $<0.01$ & 0 & 0.88 \\
\hline Polyhydramnios & WeChat & 5 & $R R=0.17$ & $(0.08,0.35)$ & $<0.01$ & 0 & 0.99 \\
\hline
\end{tabular}

GDM Gestational diabetes mellitus, $\mathrm{HbAlc}$ glycated haemoglobin, $2 \mathrm{hBG}$ 2-h postprandial blood glucose, FBG fasting blood glucose, $P I H$ pregnancy-induced hypertension, $N I C U$ neonatal intensive care unit, $R R$ relative risk, $C l$ confidence interval, $M D$ mean difference, $T M$ telemedicine

at existing clinics due to geographical constraints [50, 51].TM provides a convenient channel for communication between medical staff and patients, where medical staff could monitor the health status of patients in realtime, allowing patients to obtain individual treatment plans and disease-related knowledge of their own conditions, which may greatly improve the compliance of patients and further contribute to lower glycaemic levels $[4,14]$. Some studies have shown that the psychological status of pregnant women also has a certain impact on pregnancy outcomes [52]. Timely communication between doctors and patients through the TM platform may reduce the anxiety of pregnant women and further reduce the risk of adverse outcomes on the basis of controlling the level of blood glucose.
Our finding on HbA1c was consistent with existing meta-analyses involving patients with type I diabetes and/or type II diabetes $[8,9,53]$. Marcolino et al. conducted a meta-analysis of 13 RCTs with 4207 diabetic patients and concluded that TM strategies were associated with improved HbA1c in patients with type I and II diabetes. Zhai et al. carried out a meta-analysis of 35 RCTs and found evidence of a reduction in HbA1c in the TM group among patients with type II diabetes mellitus. Wang et al. demonstrated that the TM intervention was inversely associated with the level of HbA1c in their meta-analysis involving a total of 602 type I diabetic patients. HbA1c is recognized as a key and valuable indicator of the effectiveness of treatment in diabetic patients, and a $1 \%$ reduction in $\mathrm{HbA} 1 \mathrm{c}$ was associated with 
Table 4 Subgroup analyses of studies using different TM patterns

\begin{tabular}{|c|c|c|c|c|c|c|c|}
\hline \multirow[t]{2}{*}{ Outcome } & \multirow{2}{*}{$\begin{array}{l}\text { TM } \\
\text { pattern }\end{array}$} & \multirow{2}{*}{$\begin{array}{l}\text { No. } \\
\text { of } \\
\text { trials }\end{array}$} & \multicolumn{3}{|c|}{ Pooled effect } & \multicolumn{2}{|c|}{ Heterogeneity } \\
\hline & & & Effect size & $95 \% \mathrm{Cl}$ & $P$ & $P^{2}$ & $P$ \\
\hline \multirow[t]{2}{*}{ Change in $\mathrm{HbA} 1 \mathrm{c}$} & Group 1 & 5 & $\mathrm{MD}=-0.34$ & $(-0.67,-0.01)$ & 0.04 & 94 & $<0.01$ \\
\hline & Group 2 & 3 & $M D=-0.63$ & $(-1.11,-0.14)$ & 0.01 & 83 & $<0.01$ \\
\hline \multirow[t]{3}{*}{ Change in FBG } & Group 1 & 8 & $M D=-0.25$ & $(-0.43,-0.08)$ & $<0.01$ & 56 & 0.03 \\
\hline & Group 2 & 4 & $M D=-0.29$ & $(-0.65,0.06)$ & 0.11 & 84 & $<0.01$ \\
\hline & Group 3 & 6 & $M D=-0.64$ & $(-1.26,-0.02)$ & 0.04 & 94 & $<0.01$ \\
\hline \multirow[t]{3}{*}{ Change in $2 \mathrm{hBG}$} & Group 1 & 4 & $\mathrm{MD}=-0.29$ & $(-0.70,0.11)$ & 0.15 & 26 & 0.26 \\
\hline & Group 2 & 4 & $M D=-0.60$ & $(-1.92,0.72)$ & 0.37 & 97 & $<0.01$ \\
\hline & Group 3 & 5 & $M D=-1.55$ & $(-2.29,-0.81)$ & 0.02 & 92 & $<0.01$ \\
\hline \multirow[t]{3}{*}{ Caesarean section } & Group 1 & 10 & $R R=0.96$ & $(0.73,1.27)$ & 0.77 & 65 & $<0.01$ \\
\hline & Group 2 & 3 & $R R=0.67$ & $(0.57,0.92)$ & 0.01 & 0 & 0.50 \\
\hline & Group 4 & 5 & $R R=0.67$ & $(0.57,0.80)$ & $<0.01$ & 0 & 0.73 \\
\hline \multirow[t]{2}{*}{ PIH or preeclampsia } & Group 1 & 7 & $R R=0.69$ & $(0.44,1.08)$ & 0.10 & 16 & 0.31 \\
\hline & Group 3 & 3 & $\mathrm{RR}=0.44$ & $(0.35,0.56)$ & $<0.01$ & 0 & 0.98 \\
\hline Premature rupture of membranes & Group 1 & 4 & $\mathrm{RR}=0.76$ & $(0.40,1.44)$ & 0.40 & 22 & 0.28 \\
\hline \multirow[t]{4}{*}{ Macrosomia } & Group 1 & 7 & $\mathrm{RR}=0.95$ & $(0.55,1.65)$ & 0.85 & 32 & 0.19 \\
\hline & Group 2 & 5 & $\mathrm{RR}=0.43$ & $(0.20,0.92)$ & 0.03 & 48 & 0.10 \\
\hline & Group 3 & 3 & $\mathrm{RR}=0.21$ & $(0.09,0.48)$ & $<0.01$ & 61 & 0.08 \\
\hline & Group 4 & 3 & $\mathrm{RR}=0.44$ & $(0.27,0.71)$ & $<0.01$ & 0 & 0.64 \\
\hline \multirow[t]{2}{*}{ Neonatal hypoglycaemia } & Group 1 & 7 & $\mathrm{RR}=1.20$ & $(0.81,1.78)$ & 0.36 & 0 & 82.4 \\
\hline & Group 2 & 3 & $R R=0.36$ & $(0.22,0.60)$ & $<0.01$ & 0 & 0.78 \\
\hline \multirow[t]{2}{*}{ Preterm birth } & Group 1 & 7 & $\mathrm{RR}=0.42$ & $(0.22,0.80)$ & $<0.01$ & 20 & 0.27 \\
\hline & Group 3 & 3 & $\mathrm{RR}=0.21$ & $(0.13,0.32)$ & $<0.01$ & 16 & 0.30 \\
\hline Polyhydramnios & Group 3 & 3 & $\mathrm{RR}=0.17$ & $(0.09,0.32)$ & $<0.01$ & 0 & 0.92 \\
\hline Admission to NICU & Group 1 & 7 & $R R=0.88$ & $(0.56,1.40)$ & 0.60 & 20 & 0.28 \\
\hline Neonatal jaundice or hyperbilirubinemia & Group 1 & 5 & $\mathrm{RR}=1.09$ & $(0.69,1.71)$ & 0.71 & 0 & 0.72 \\
\hline NARDS & Group 1 & 4 & $\mathrm{RR}=0.81$ & $(0.37,1.77)$ & 0.60 & 0 & 0.47 \\
\hline
\end{tabular}

Group 1: real-time monitoring and feedback, Group 2: health education and question answering, Group 3: real-time monitoring and feedback + health education and question answering, Group 4: real-time monitoring and feedback + health education and question answering + peer support

GDM Gestational diabetes mellitus, HbA1c glycated haemoglobin, $2 \mathrm{hBG}$ 2-h postprandial blood glucose, FBG fasting blood glucose, $P I H$ pregnancy-induced hypertension, NICU neonatal intensive care unit, $R R$ relative risk, $C l$ confidence interval, $M D$ mean difference, $T M$ telemedicine

21 and $37 \%$ risk reduction in diabetes-related death and microvascular complications, respectively, which would reduce the healthcare cost [54].

According to the results of meta-regression and subgroup analyses, the effectiveness of TM for GDM management may vary by the location of the study, the average age of pregnant women, the gestational age at enrolment, the proportion of primipara and the type of TM. The gestational age at enrolment reflected the period of the interventions, and earlier interventions could have led to a more significant change in HbA1c and $2 \mathrm{hBG}$ in this study, which illustrated the effect of TM to some extent. The location of the study may represent the inconsistency of scientific conditions and levels as well as various races of participants, resulting in heterogeneity among studies. Furthermore, the average age of pregnant women and the proportion of primipara can represent the physical and mental condition of pregnant women to some extent [55]. In addition, we found that WeChat interventions were more effective than other types of TM tools on more outcomes. Compared to other interventions, as a popular social app, WeChat was more convenient and accessible in daily life, and allowed patients to upload their glycaemic data, communicate and discuss with each other, reduce their psychological burden, enhance their confidence and receive more health information in many forms [16]. Considering the good operability and accessibility of social apps, it is believed that social apps will play essential roles in the clinical management of GDM in the future. Moreover, the subgroup analysis of the patterns of TM interventions demonstrated that the patterns of TM interventions may be 


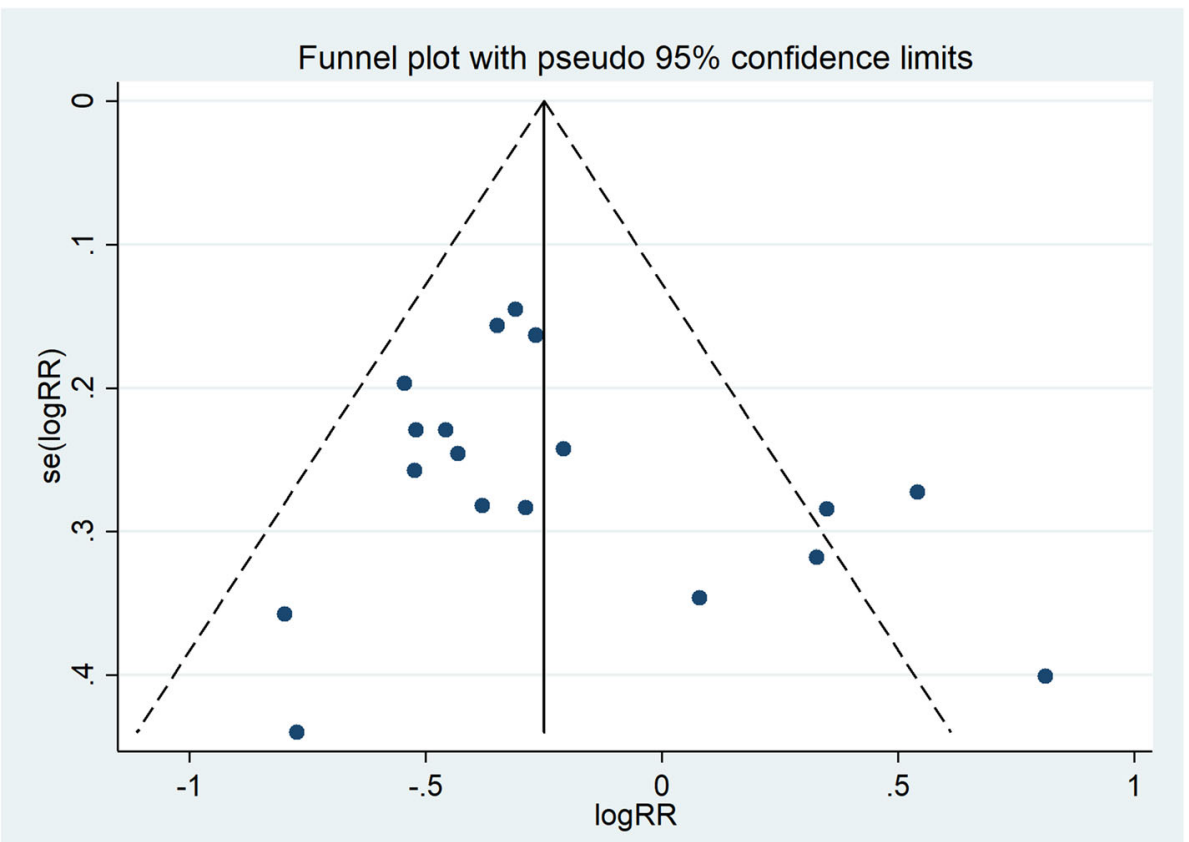

Fig. 4 The funnel plot of the incidence of caesarean section

another factor of the effectiveness. More comprehensive interventions could provide better management effects than simple interventions on most outcomes. The above results further suggested that what the TM is delivering or the strength of interventions is more important than the way it is delivered. And we should fully combine the characteristics of each TM tool and make full use of its functions to improve the management.

The results of TSA showed that cumulative Z-values of the change in HbA1c, 2hBG, and FBG, and the incidence of caesarean section, $\mathrm{PIH}$ or preeclampsia, premature rupture of membranes, premature birth, neonatal asphyxia, and polyhydramnios all surpassed the monitoring boundary or RIS line in TSA, which confirmed conclusive and sufficient evidence. In addition, cumulative Z-values of the incidence of macrosomia, neonatal hypoglycaemia, NICU, neonatal jaundice or hyperbilirubinemia, and NARDS suggest that the current evidence was not sufficient to fully indicate that the cumulative evidence reached a stable state and that further research on the comparison between TM and standard care is still needed to strengthen the evidence.

We embrace and appreciate that all scientific research has limitations, and our study had several to consider. Firstly, the standard care protocols and the diagnostic methods of GDM were not consistent among the included studies, which may have led to inconsistency and

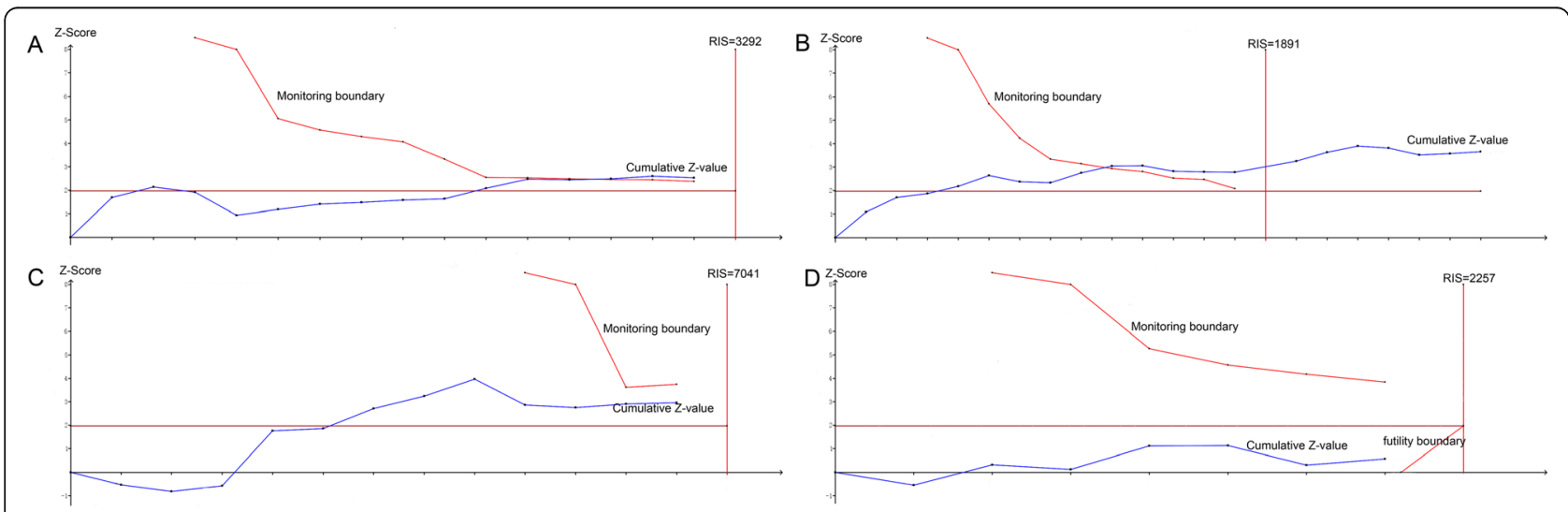

Fig. 5 TSA results of the change in $2 \mathrm{hBG}(\mathbf{a})$, change in FBG (b), incidence of neonatal hypoglycaemia (c) and incidence of admission to NICU (d) 
incomparability of the results. Secondly, random sequence generation methods and allocation concealment in most of the studies were not explicitly described which may have led to inaccurate assessment of research quality. Thirdly, blinding of healthcare providers and participants was not feasible in any of the included studies due to the nature of the TM intervention, and patients in the control group may obtain health information from other sources, which may cause biases in effect size. Finally, only literature published in Chinese and English were included in this study which may have resulted in the publication bias or language bias.

\section{Conclusions}

In conclusion, telemedicine interventions contributed to beneficial impacts on the glycaemic level, and some maternal and neonatal/foetal complications in patients with gestational diabetes mellitus compared to the effects of standard care. The application of telemedicine in the clinical management of gestational diabetes mellitus may be advisable. Due to the limitation of systematic reviews and meta-analyses, an individual patient data metaanalysis or a well-designed randomized study may provide more important information for further management. Considering the high-speed development of information and communication technology and the complexity of gestational diabetes mellitus, the effectiveness of telemedicine for gestational diabetes mellitus needs to be further studied in the future.

\section{Supplementary information}

Supplementary information accompanies this paper at https://doi.org/10. 1186/s12884-020-02892-1.

Additional file 1. PRISMA checklist.

Additional file 2. The Web of Science search strategy.

Additional file 3. Detailed descriptions of TM interventions of included studies.

Additional file 4: Table S1. Additional subgroup analyses.

\section{Abbreviations}

GDM: Gestational diabetes mellitus; HbA1c: glycated haemoglobin; 2hBG: 2-h postprandial blood glucose; FBG: Fasting blood glucose; PIH: Pregnancyinduced hypertension; NICU: Neonatal intensive care unit; NARDS: Neonatal acute respiratory distress syndrome; RCT: Randomized controlled trials; TSA: Trial sequential analysis; RR: Relative risk; Cl: Confidence interval; MD: Mean difference; TM: Telemedicine; RRR: Relative risk reduction; RIS: Required information size; CENTRAL: Cochrane Central Register of Randomized Control Trials; CNKI: Chinese National Knowledge Infrastructure; CBM: China Biology Medicine

\section{Acknowledgements}

Not applicable.

\section{Authors' contributions}

$X Y, W X$, and PD designed the study. WX and YQ extract data. WX, MW and $B Y$ performed data analyses and $W X$ and $X Y$ wrote the first draft of the manuscript. All authors (WX, PD, YQ, MW, BY and XY) read the manuscript drafts for intellectual content, suggested revisions and approved the final draft for submission.

\section{Funding}

This work was supported by the National Natural Science Foundation of China (No. 81673274) and the Nanjing Municipal Commission of Science and Technology (No. 201715077). The funding bodies did not contribute to the design of the study and collection, analysis, and interpretation of data and writing the manuscript.

\section{Availability of data and materials}

The datasets used and/or analyzed during the current study are available from the corresponding author on reasonable request.

Ethics approval and consent to participate Not applicable.

Consent for publication

Not applicable.

\section{Competing interests}

The authors declare that they have no competing interests.

\section{Author details}

'Department of Epidemiology and Health Statistics, School of Public Health, Southeast University, Nanjing, China. ${ }^{2}$ Jiangsu Provincial Center for Disease Control and Prevention, Nanjing, China. ${ }^{3} Z$ hongda Hospital, Southeast University, Nanjing, China.

Received: 23 December 2019 Accepted: 24 March 2020

Published online: 06 April 2020

\section{References}

1. Cho NH, Shaw JE, Karuranga S, Huang Y, da Rocha Fernandes JD, Ohlrogge AW, Malanda B. IDF diabetes atlas: global estimates of diabetes prevalence for 2017 and projections for 2045. Diabetes Res Clin Pract. 2018;138:271-81.

2. Johns EC, Denison FC, Norman JE, Reynolds RM. Gestational diabetes mellitus: mechanisms, treatment, and complications. Trends Endocrinol Metab. 2018;29(11):743-54.

3. Kim Y-S, Kim H-S, Kim Y-L. Effects of a web-based self-management program on the behavior and blood glucose levels of women with gestational diabetes mellitus. Telemed J E Health. 2019;25(5):407-14.

4. Miremberg H, Ben-Ari T, Betzer T, Raphaeli H, Gasnier R, Barda G, Bar J, Weiner $\mathrm{E}$. The impact of a daily smartphone-based feedback system among women with gestational diabetes on compliance, glycaemic control, satisfaction, and pregnancy outcome: a randomized controlled trial. Am J Obstet Gynecol. 2018;218(4):453.e1-7.

5. Amer Diabet A. Standards of medical care in diabetes-2011 american diabetes association. Diabetes Care. 2011;34:S11-61.

6. Guo H, Zhang Y, Li P, Zhou P, Chen LM, Li SY. Evaluating the effects of mobile health intervention on weight management, glycaemic control and pregnancy outcomes in patients with gestational diabetes mellitus. J Endocrinol Investig. 2019;42(6):709-14.

7. Mackillop L, Hirst JE, Bartlett KJ, Birks JS, Clifton L, Farmer AJ, Gibson O, Kenworthy $Y$, Levy JC, Loerup L, et al. Comparing the efficacy of a Mobile phone-based blood glucose management system with standard Clinic Care in Women with Gestational Diabetes: randomized controlled trial. JMIR Mhealth Uhealth. 2018;6(3):e71.

8. Wang $X$, Shu W, Du J, Du M, Wang P, Xue M, Zheng H, Jiang Y, Yin S, Liang $D$, et al. Mobile health in the management of type 1 diabetes: a systematic review and meta-analysis. BMC Endocr Disord. 2019;19:21.

9. $Y-k$ Z, Zhu W-j, Y-I C, D-x S, Zhao J. Clinical- and cost-effectiveness of telemedicine in type 2 diabetes mellitus: a systematic review and metaanalysis. Medicine. 2014;93(28):e312.

10. Boccalandro EA, Dallari G, Mannucci PM. Telemedicine and telerehabilitation: current and forthcoming applications in haemophilia. Blood Transfus. 2019;17(5):385-90.

11. Chirra M, Marsili L, Wattley L, Sokol LL, Keeling E, Maule S, Sobrero G, Artusi CA, Romagnolo A, Zibetti M, et al. Telemedicine in neurological disorders: opportunities and challenges. Telemed J E Health. 2019;25(7):541-50. 
12. Lee TC, Kaiser TE, Alloway R, Woodle ES, Edwards MJ, Shah SA. Telemedicine based remote home monitoring after liver transplantation: results of a randomized prospective trial. Ann Surg. 2019;270(3):564-72.

13. von Storch K, Graaf E, Wunderlich M, Rietz C, Polidori MC, Woopen C. Telemedicine-assisted self-management program for type 2 diabetes patients. Diabetes Technol Ther. 2019;21(9):514-21.

14. Ming WK, Mackillop LH, Farmer AJ, Loerup L, Bartlett K, Levy JC, Tarassenko L, Velardo C, Kenworthy Y, Hirst JE. Telemedicine Technologies for Diabetes in pregnancy: a systematic review and meta-analysis. J Med Internet Res. 2016;18(11):e290

15. Sweileh WM, Al-Jabi SW, AbuTaha AS, Zyoud SH, Anayah FMA, Sawalha AF. Bibliometric analysis of worldwide scientific literature in mobile - health: 2006-2016. BMC Med Inform Decis Mak. 2017;17:72.

16. Mao L, Lu J, Zhang Q, Zhao Y, Chen G, Sun M, Chang F, Li X. Family-based intervention for patients with type 2 diabetes via WeChat in China: protocol for a randomized controlled trial. BMC Public Health. 2019;19:381.

17. Rasekaba TM, Furler J, Blackberry I, Tacey M, Gray K, Lim K. Telemedicine interventions for gestational diabetes mellitus: a systematic review and meta-analysis. Diabetes Res Clin Pract. 2015;110(1):1-9.

18. Gao Q, Chen W, Wang L. A study on the application of mobile phone APP gestational diabetes mellitus management software in the management of gestafional diabetes. J Nurs Adm. 2017;17(6):447-9.

19. Hua Y. Application of mobile application software in humanistic care of pregnant women with gestational diabetes. J Nurs Train. 2018;33(11):1018-21.

20. Jiang $W$. The effect of WeChat follow-up on compliance behavior of pregnant women with gestational diabetes mellitus. Chin Commun Doc. 2016;32(30):144-5.

21. Lu Y, Qian L, Cai G, Zhao X, Lu H. Effects of information-based nursing intervention on patients with gestational diabetes mellitus. J Qilu Nurs. 2017:23(16):41-3.

22. Su H, Sun $\mathrm{H}$, Yang J. Application of remote multiple management in gestational diabetes. J Kunming Med Univ. 2018;39(9):33-6.

23. Ge Y, Yan S, Wang S, Zhao Y, Ding C. Exploring application of WeChat for gestational diabetes mellitus management. Chin J Pract Nurs. 2017;33(36):2819-22.

24. Xiao L. Application research on the health education of patients with diabetes in pregnancy based on the WeChat platform. China Health Indust. 2016;13(26):101-3.

25. Liberati A, Altman DG, Tetzlaff J, Mulrow C, Gotzsche PC, loannidis JPA, Clarke M, Devereaux PJ, Kleijnen J, Moher D. The PRISMA statement for reporting systematic reviews and meta-analyses of studies that evaluate healthcare interventions: explanation and elaboration. BMJ. 2009;339:b2700.

26. Higgins JPT, Altman DG, Gotzsche PC, Jueni P, Moher D, Oxman AD, Savovic J, Schulz KF, Weeks L, Sterne JAC, et al. The Cochrane Collaboration's tool for assessing risk of bias in randomised trials. BMJ. 2011;343:d5928.

27. Higgins JP, Altman DG. Assessing risk of bias in included studies. In: Higgins JP, Green S, editors. Cochrane handbook for systematic reviews of interventions. New Jersey: Wiley; 2008. pp. 187-241.

28. Olivier J, May WL, Bell ML. Relative effect sizes for measures of risk. Commun Stat Theory Methods. 2017:46(14):6774-81.

29. Carral F, del Carmen AM, Jesus Fernandez J, Gonzalez C, Pinero A, Garcia G, Canavate C, Isabel Jimenez A, Garcia C. Web-based telemedicine system is useful for monitoring glucose control in pregnant women with diabetes. Diabetes Technol Ther. 2015;17(5):349-54.

30. Dalfra MG, Nicolucci A, Lapolla A. Tisg: the effect of telemedicine on outcome and quality of life in pregnant women with diabetes. J Telemed Telecare. 2009;15(5):238-42.

31. Given JE, Bunting BP, O'Kane MJ, Dunne F, Coates VE. Tele-mum: a feasibility study for a randomized controlled trial exploring the potential for telemedicine in the diabetes Care of those with gestational diabetes. Diabetes Technol Ther. 2015;17(12):880-8.

32. Homko CJ, Santamore WP, Whiteman V, Bower M, Berger P, GeifmanHoltzman O, Bove AA. Use of an internet-based telemedicine system to manage underserved women with gestational diabetes mellitus. Diabetes Technol Ther. 2007:9(3):297-306.

33. Homko CJ, Deeb LC, Rohrbacher K, Mulla W, Mastrogiannis D, Gaughan J, Santamore WP, Bove AA. Impact of a telemedicine system with automated reminders on outcomes in women with gestational diabetes mellitus Diabetes Technol Ther. 2012;14(7):624-9.

34. Perez-Ferre N, Galindo M, Dolores Fernandez M, Velasco V, Runkle I, de la Cruz Jose M, Martin Rojas-Marcos P, del Valle L, Calle-Pascual AL. The outcomes of gestational diabetes mellitus after a telecare approach are not inferior to traditional outpatient clinic visits. Int J Endocrinol. 2010;2010:386941.

35. Rasekaba TM, Furler J, Young D, Liew D, Gray K, Blackberry I, Lim WK. Using technology to support care in gestational diabetes mellitus: quantitative outcomes of an exploratory randomised control trial of adjunct telemedicine for gestational diabetes mellitus (TeleGDM). Diabetes Res Clin Pract. 2018;142:276-85.

36. Yang $P, L O W, H e$ Z, Xiao XM. Medical nutrition treatment of women with gestational diabetes mellitus by a telemedicine system based on smartphones. J Obstet Gynaecol Res. 2018;44(7):1228-34.

37. Carolan-Olah M, Sayakhot P. A randomized controlled trial of a web-based education intervention for women with gestational diabetes mellitus. Midwifery. 2019;68:39-47.

38. Zhang S. Observation of the effect of mobile home care platform on blood glucose and quality of life in patients with gestational diabetes mellitus. World Latest Med Inform. 2018;18(74):284-93.

39. Zhao Z, Qian J, Mo Y, Zhun Y, Jiang P, Long W, Xu J, Huo X. Effects of mobile home care platform on blood glucose and quality of life in gestational diabetes mellitus patients. J Nurs Train. 2018:33(06):490-2.

40. Zeng C. The effects of psychological nursing on anxiety of gestational diabetes mellitus patients based on WeChat Platform. Chin J Health Psychol. 2017;25:8.

41. Fang T. Effects of diet control and WeChat interactive model on management of patients with gestational diabetes mellitus. Today Nurse. 2017;11:64-6.

42. Huang $X$, Yang $Q, X u Z$, Liang $X$. Effect of WeChat on nutrition instructions to women of advanced maternal age with gestational diabetes mellitus. Modern Clin Nurs. 2016;15(4):51-4

43. Jiang Z, Huang $Y$, Yuan $X$, Chen $Y$, Chen P. Pregnancy outcomes in women with gestational diabetes mellitus by WeChat. Med Innov China. 2017;14(4):8-11.

44. Jiang Z, Chen Y, Yuan X, Huang Y, Chen P. Analysis of the value of individual health education and nutrition guidance on WeChat platform on pregnancy outcome of pregnant women with gestational diabetes mellitus. Chin J Pharm Econ. 2019;14(04):80-3.

45. Liu H. Application Value of Long Distance Blood Glucose Management in Gestational Diabetes Mellitus. Med Innov China. 2018;15:21.

46. Luo W. Research on the influence factors of gestational diabetes neonatal weight based on WeChat platform. Prog Obstetr Gynecol. 2017;26:10.

47. Shao Y, He G, Xu X, He J, Wu P. Education via WeChat improves glucose control and pregnant outcomes in women with gestational diabetes mellitus. Chin J Perinat Med. 2018;21(10):678-82.

48. Weng F, Ma X. Research of nursing effect on elderly puerpera with gestational diabetes mellitus based on health education of WeChat platform. Nurs Pract Res. 2018;15(3):81-3.

49. Yang F, Wei Z, Hu H, Lu W, Cai C. Effect of WeChat group family bed on management of gestational diabetes mellitus. Jiangsu Med J. 2015;41(11):1332-4.

50. Batsis JA, Pletcher SN, Stahl JE. Telemedicine and primary care obesity management in rural areas - innovative approach for older adults? BMC Geriatr. 2017;17(1):6.

51. Mehrotra A, Jena AB, Busch $A B$, Souza J, Uscher-Pines L, Landon BE. Utilization of telemedicine among rural Medicare beneficiaries. JAMA. 2016; 315(18):2015-6.

52. Asgharian B, Sehhatie F, Mirghafourvand M. The effect of training pregnant women and their Husband's on the anxiety in pregnant women with previous adverse pregnancy outcomes: a controlled randomized clinical trial. J Foetal Med. 2019;6(1):17-23.

53. Marcolino MS, Maia JX, Moreira Alkmim MB, Boersma E, Ribeiro AL. Telemedicine application in the Care of Diabetes Patients: Systematic Review and Meta-Analysis. PLoS One. 2013;8:11.

54. Stratton IM, Adler Al, Neil HA, Matthews DR, Manley SE, Cull CA, Hadden D, Turner RC, Holman RR. Association of glycaemia with macrovascular and microvascular complications of type 2 diabetes (UKPDS 35): prospective observational study. BMJ. 2000:321(7258):405-12.

55. Sydsjo G, Pettersson ML, Bladh M, Svanberg AS, Lampic C, Nedstrand E. Evaluation of risk factors' importance on adverse pregnancy and neonatal outcomes in women aged 40years or older. BMC Pregnancy Childbirth. 2019;19: 92.

\section{Publisher's Note}

Springer Nature remains neutral with regard to jurisdictional claims in published maps and institutional affiliations. 